\title{
WORK-LIFE BALANCE FOR SUSTAINABLE DEVELOPMENT IN MALAYSIAN HIGHER EDUCATION INSTITUTIONS: FAD OR FACT?
}

\section{Magdalene Ang Chooi Hwa}

Centre for Research on Women and Gender (KANITA), Universiti Sains Malaysia, Pulau Pinang, MALAYSIA

E-mail: ang.magdalene@gmail.com

Published online: 15 April 2020

To cite this article: Ang, M.C.H. 2020. Work-life balance for sustainable development in Malaysian higher education institutions: Fad or fact? Kajian Malaysia 38(Supp.1): 33-50. https://doi.org/10.21315/km2020.38.s1.3

To link to this article: https://doi.org/10.21315/km2020.38.s1.3

\begin{abstract}
The mainstream literature abounds with the challenges and effects of lack of worklife balance (WLB), but little is known about WLB experience and coping strategies that may be unique to women in academe. Knowledge in this area assumes significance amid the increased work intensification experienced by academics in recent years. Premised on the notion that WLB is not a passing fad but a catalyst for sustainable development, this article documents the findings of a qualitative study of 11 full-time women academic staff in Malaysian universities. Majority of the women perceived their WLB to be reasonable despite experiencing increased work intensification. The findings imply that how they cope with work and family situations are important to a healthy WLB. Research and policy implications for sustainable work and growth are discussed.
\end{abstract}

Keywords: work-life balance, sustainability, coping strategies, women, academia

\section{INTRODUCTION}

Fundamental changes in the context and conditions of academia in many parts of the world have been rampant in recent years. These changes are expected to become more rapid and profound with the dawn of the Fourth Industrial Revolution (IR4.0). The higher education scenario in Malaysia is similarly filled with new challenges brought by globalisation, transition to knowledge-based society and technological advancements (Safiah et al. 2015). Academics in Malaysia currently 
undergo numerous reforms in their work nature. Their work demands have also intensified (Bexley, Arkoudis and James 2013), causing spillovers and the blurring of boundaries between work and family which can subsequently impinge on their work-life balance (WLB) (Agosti, Bringsen and Andersson 2017). According to Kinman and Jones (2008), academics tend to experience more challenges in maintaining a healthy WLB when compared to other professional groups. One may argue that this should not be the case given that academics generally enjoy spatial and temporal flexibility in their work (Lewis 2016). However, flexible working hours and schedules may backfire in that work and non-work contexts are often blurred (Littig 2008). The result is overwork and working pattern norms that can contribute to difficulty in managing work- and non-work obligations (Acker and Armenti 2007). Greenhaus, Collins and Shaw (2003) contend that academics' WLB is important as it helps to create knowledge to all sectors of society today. The lack of balance between work and family life among academics will hence affect all other sectors.

A review of the WLB literature unearthed only a handful of research focusing on academics and students. For example, Bexley, Arkoudis and James (2013) looked at the work intensification and WLB of Australian academics; Lewis (2016) examined the WLB of Swiss lecturers, while Kinman and Jones (2008) investigated the WLB and well-being of UK academic staff; Kuo et al. (2018) explored the role of cultural coping behaviours on the relationships between academic stress and psychosocial well-being outcomes of students, while Achour and Boerhannoeddin (2011) studied religiosity as a coping strategy among Malaysian women academics. It appears that not much emphasis has been given to the role of gender in understanding academics' WLB. Although WLB concerns both genders, the incidences of work-life imbalance are reportedly more common among women than men (Acker and Armenti 2007; Ajayi, Ojo and Mordi 2015). In a society characterised by conflicting obligations and roles for women (Ajayi, Ojo and Mordi 2015), and more so with the demise of the so-called "male breadwinner model", women now seem to be shouldering a "double burden" of both paid and unpaid work (ILO 2017). Hence, the gendered expectations of family obligations and parenting coupled with the intensified work demands and current expectations from academics raise gender issues worth addressing (Achour and Boerhannoeddin 2011).

This article is guided by two main research questions, (1) what are women academics' experiences of WLB? and (2) what coping strategies they engage in to effectively manage work and family obligations? Knowledge in this area offers important implications for policy and research with regard to successful management of WLB, which can ultimately support sustainable development initiatives for women academics. The article is structured in the following manner. 
It opens with some background literature on WLB and proposes WLB as a catalyst for sustainable development, particularly for women academics. The discussion continues with the methodology employed in the study. Then the findings are presented against what has been reported in the extant literature. The article concludes with some final considerations for future research.

\section{WLB FOR SUSTAINABLE DEVELOPMENT}

Littig (2008) postulates that WLB is fundamental to sustainable development which is ultimately about improving the quality of life for every individual. What this means is that WLB is an important antecedent of people's well-being, work commitment, productivity and performance, all of which are fundamental to organisational sustainability and success. WLB is as such not merely a buzzword or a fad but is in fact a catalyst for sustainable human development in any organisation. As propounded by Rao (2017) "sustainable human development can occur only when there is a reasonable WLB" (p. 706). Littig (2008) similarly emphasises "the necessity of embedding WLB policies into an integrated sustainable policy mix" (p. 13).

In the context of higher education, WLB can positively impact academics' roles, commitment and engagement (Gatta and Roos 2004) which are vital to the delivery of quality education and ultimately the performance, success and sustainability of the university. The high performing university consequently contributes to the sustainable development goals of the nation. On the Malaysian front, the significance of WLB in achieving the National Transformation 2050's (TN2050) goals is highlighted when the 2018 budget provided more allocations to improve Malaysians' WLB (The Star 2017). In a more recent development, the Malaysian government launched the National Workforce Human Capital Development Blueprint 2018-2025 on 29 January 2018. The blueprint is part of the Human Resources Development Fund's efforts to specifically address workforce challenges associated with IR4.0, digitisation and automation, and generally to drive the government's human capital development agenda. While upskilling, reskilling and multiskilling our human capital is indeed crucial for future-proofing Malaysian talent for the dawn of the new era, this article argues that there should also be an emphasis on the physical and mental well-being of the workforce that will help realise the objectives of the blueprint. In this light, this article advocates successful management of WLB as a catalyst in sustaining the human capital development agenda for Malaysian higher education. Linking the WLB discourse to sustainability provides another advantage in the form of the potential for gender mainstreaming sustainability policies (Littig 2008). 


\section{WLB: Concept and Effects}

WLB can be simply defined as the attempt to meet work- and non-work obligations (Lewis 2016). In recent years, WLB is also associated with flexible work offerings characterised by temporal and spatial work practices in organisations which are deemed to be beneficial to employees (Lewis 2016). Academic jobs, however, have been little affected by this trend (Lewis 2016), in part due to the nature of academic job roles, such as taking work home and publishing demands for promotion and/ or tenure (Acker and Armenti 2007). Academics may as such have fewer WLB expectations (Acker and Armenti 2007).

Concurring with the perspective that WLB is key to sustainable development, a healthy WLB is seen as "a lifestyle where an individual's habits and actions result in the sustainable growth and development of his/her health, wealth, career, family relationships, social relationships and fulfilment and enjoyment of life (Lanthois 2017). Clearly, WLB does not occur by itself but requires conscious efforts at different levels (Rao 2017). The current article adopts this concept of a healthy WLB which strives for a better reconciliation of work and family spheres of life through academics' habits and actions (i.e., coping strategies and/or lifestyles). The definition jives with the person-environment fit theory (Edwards and Rothbard 2000) which spells out three sets of factors which can influence WLB. The first is accessibility of resources (Agosti, Bringsen and Andersson 2017), second, the extent and intensity of work and family demands (Gatta and Roos 2004), and third the use of adaptive strategies (Pitt-Catsouphes et al. 2007). Quick, Henly and Quick (2004) opine that individuals need to assume an active role in the management of their work duties, family commitments and self-imposed expectations. This is achieved by understanding the source of the demands that results in conflicts, making appropriate choices and using a range of coping strategies.

WLB has been found to enhance employee well-being, work commitment, engagement, productivity and performance (Deery and Jago 2009; Rao 2017). At the same time, it decreases psychological stress, health problems, work withdrawal and intention to quit (Goo, Ang and Goi 2018; Lunau et al. 2014). WLB in academia can affect the quality of higher education (Kinman and Jones 2008). Research on the effects of decreased WLB has also highlighted gender issues such as schedule complexity for women who must juggle between work and family obligations (Acker and Armenti 2007; Ang et al. 2018; Gatta and Roos 2004; Santos and Cabral-Cardoso 2008). 


\section{WLB Gender Differences}

Recent literature recognises that WLB is an issue for both men and women (Parker and Wang 2013), thus underscoring the important role of gender in shaping our understanding of WLB. Research shows that work and personal life domains can influence one another in positive and negative ways (Grawitch, Barber and Justice 2010). Work-to-family enrichment (i.e., when positive experiences at work leads to a richer family life) is found to be significant for men but not for women (TanWilson and Stamp 2015). On the contrary, family-to-work enrichment (i.e., a spillover of fulfilling experiences as a family member to work) was significant for women but not for men (Tan-Wilson and Stamp 2015).

Men and women are also found to differ in terms of the strategies they use to strike a balance between work and family (Bray et al. 2001). To accommodate family commitments, for example, women are more likely than men to adjust their work by adjusting work schedules, holding part-time job, choosing less demanding work, switching careers, or relinquishing career advancement opportunities (Adema 2013). Rothbard (2001) opines that the above noted differences are ascribed to men and women having internalised diverging societal expectations, that men have principal responsibility for work and women are primarily responsible for the family. Consequently, women still have to shoulder the bigger share of housework and childcare even when they are fully employed (Parker and Wang 2013). The literature on work and family issues by Ajayi, Ojo and Mordi (2015) and Ang et al. (2018) consistently cautions that balancing a successful career with personal and family aspects of life can be challenging, more so for women than it is for men. However, even if conflict is a consequence of engaging in work and family roles, how people cope with conflicts could be more important since it can determine personal outcomes (Hertz 1999).

\section{Coping Strategies for Improved WLB}

For over 30 years, research on work-family dynamics has been dominated by the "conflict perspective" which views work and family as conflicting role responsibilities (Greenhaus, Collins and Shaw 2003). Lower levels of conflict are as such associated with better WLB and vice versa (Frone 2003). However, this perspective has been criticised for portraying employees as victims of their own work-family conflicts (Frone 2003). Researchers are thus encouraged to begin examining why some individuals fare better than others when encountering conflict and stress in their lives (Ferguson et al. 2012). 
This emerging research area by Ferguson et al. (2012) is founded on the notion that employees are resilient and capable of effectively utilising their own coping strategies to improve WLB. Gowan, Riordan and Gatewood (1999) described coping strategies as "attempts by an individual to manage the external and internal demands resulting from a stressor" (p. 77). Haar (2006) expanded this definition by adding that "coping strategies are about dealing with demands that are significant and, typically, unusual in nature" (p. 149). It follows that coping strategies when employed effectively to deal with stressors such as work intensification may lead to positive outcomes (Haddock et al. 2001; Pitt-Catsouphes et al. 2007). Studies by Winefield et al. (2003) and Managing Work/Life Balance International (2007) have affirmed that despite increased work intensification and conflicting role demands, individuals who employ effective coping tactics are found to be satisfied with their work and have reasonable WLB perception. Apart from individuals' coping strategies, the importance of joint contribution of both employers and employees to the successful management of WLB has also been recognised (Haddon and Hede 2009). However, there is empirical evidence that WLB has stronger associations with individuals' coping efforts than organisational deliberation in providing WLB programmes (Zheng et al. 2016).

The existing literature by Haddock et al. (2001), Haddon and Hede (2009) and Pitt-Catsouphes et al. (2007) documents numerous coping strategies which are effectively utilised by employees, be it at home or at work. For example, in a study of Australian lawyers, Haddon and Hede (2009) identified seven effective WLB management strategies namely boundary management, technology, leisure activities, support, flexibility, cognitive strategies and behavioural strategies. Coping strategies can also be broadly categorised as problem-focused or emotionfocused depending on the situation (Stahl and Caliguiri 2005). Problem-focused coping strategies are "displaying coping behaviours aimed at the management of the person-environment relationship," whereas emotion-focused coping strategies relate to "the regulation of emotions that result from the stress" (Stahl and Caliguiri 2005 , 604). Simply put, problem-focused coping strategies are used to address a problem directly, whereas emotion-focused coping strategies are employed to manage the feeling of distress, rather than tackling the problem itself (Achour and Boerhannoeddin 2011).

This article proposes that coping strategies are key in helping women academics improve their WLB amid the intensification of their work. Using coping strategies, women academics can become more autonomous in the creation of boundaries to carry out work- and non-work-related tasks (Lewis 2016), thus enhancing their ability to cope with temporal constraints. Only by ensuring the successful management of WLB via coping strategies and other WLB policy mix, the overall quality of life and potentials of these women can be fully realised. 


\section{RESEARCH METHODOLOGY}

\section{Instrument and Data Collection}

This research employed the qualitative research technique, i.e., in-depth interviews (IDIs). The instrument consists of open-ended questions which were derived from the extant literature on WLB and coping strategies. It also contains an introduction to the purpose of the study and an assurance of anonymity and confidentiality. The instrument was pilot-tested with five volunteers to determine its feasibility before using it in the actual IDIs. Invitations to participate in the IDIs were extended via phone calls and/or email messages to pre-selected number of women academics to ensure an almost equal representation with regard to university type (public and private) and geographic location (west and east Malaysia). By providing written consent, 21 academics agreed to participate in the study.

The IDIs began with questions tapping into demographic information such as age, marital status, number of dependents, etc. The researcher then asked the respondents to rate on a scale of one to five (with one being very low to five being very high) the levels of work intensification and WLB they experienced at the time of the study. Subsequent questions were aimed at obtaining more comprehensive data on WLB experience and coping strategies. To determine data/ thematic saturation, the interview data were reviewed after several interviews had been conducted. Data saturation was evident after conducting 11 interviews. On this basis, the researcher made the decision to stop conducting further interviews given that the purpose was "not to count opinions ... but to explore the range of ... different representations" (O'Reilly and Parker 2012, 3) of the sample.

\section{Respondent Demographics}

The sample consisted of 11 full-time women academics: six in public universities and five in private universities; six from East Malaysia and five from West Malaysia. On average, they had over eight years of work tenure, occupying academic ranks like professor (one), associate professor (two), senior lecturer (five) and lecturer (three). At the time of the survey, their ages ranged from 28 to 58 years. Regarding the respondents' ethnicity, four are Malay, four are Chinese, two are Indian and one is Kadazan. Seven respondents were married, with the remaining reported being single, divorced or widowed. All except two respondents reported having dependents (children/parents/others) living at home. 


\section{Data Analysis}

The audio recordings and transcripts from the interviews were managed with the help of ATLAS.ti, a qualitative software package. The process involved five steps namely import, code, query and visualise, annotate, and summarise. Both anticipated themes and emerging themes (i.e., issues that the respondents raised during the interviews) were derived from the data. The identification, examination, and interpretation of patterns and themes in the data were, however, performed manually to help answer the research questions.

\section{RESULTS}

This section summarises the study's key findings which reflect perceived work intensification and experience of WLB and coping strategies. To describe the findings, quotes were selected from the data to depict the themes and illustrate the intended meanings of the respondents.

\section{Work Intensification and WLB in Academia}

The mean value obtained for work intensification is $3.91(S D=0.31)$, implying that the respondents perceived the intensification of their work to be high, thus confirming past findings (e.g., Achour and Boerhannoeddin 2011; Bexley, Arkoudis and James 2013; Kinman and Jones 2008).

Our work roles and responsibilities have definitely enlarged in recent years. We're now expected to do much more in a day such as getting more research grants, more high-impact publications...developing MOOC courses. (Respondent 1, married, public university)

On perceived WLB, the data interestingly show that despite indicating that their work had intensified, slightly more than half of the respondents (marital status notwithstanding) reported a reasonable WLB $(M=3.12 ; S D=0.66)$. Three quarters of the women also commented that they fall back on some coping strategies to help mitigate their stress. Clearly, when one is an active agent in managing work and family demands, WLB can still be within reach despite increasing workloads (Haddon and Hede 2009; Quick, Henly and Quick 2004).

I think I still enjoy WLB even though my work demands have increased quite significantly over the past five or six years...maybe because I've learnt to prioritise and focus on the more important matters, be it at work or at home. (Respondent 7, married, public university) 
Do I have WLB? To some extent, yes I do. But I have to make some conscious efforts to cope with the demands of my work and personal life. (Respondent 4, married, private university)

\section{Coping Strategies}

Following Achour and Boerhannoeddin (2011), this study focuses on 10 coping strategies which are categorised as problem-focused and emotion-focused coping strategies. Problem-focused coping strategies are comprised of workplace support, familial support, other social support network, time management, working harder and work schedules adjustment. Self-talk, self-efficacy, recreational activities and religious activities are considered as emotion-focused coping tactics. A list of these coping strategies was compiled for the respondents to select and/or include additional items (if any) which best described their typical coping strategies in addressing the challenges inherent in maintaining their WLB. The results revealed that the top five most frequently endorsed strategies are familial support, workplace support, time management, recreational activities and religious activities. Work schedule adjustment, working harder, other social support network, self-efficacy and self-talk got the least number of votes in the order they appear.

Anticipated and emerging themes were further determined by prompting the women to share more about their coping strategies. The women's narratives revealed five coping strategies subsumed under the anticipated themes mentioned earlier. Additionally, two other coping strategies, i.e., satisficing and workplace culture/leadership emerged from the data.

\section{Familial support}

Support emerged as the most strongly endorsed coping technique among the respondents. More than half of the women reported tapping on sources of support at home to help them cope better with their work demands and family commitments.

Keeping WLB in academia is a challenge. But getting the needed support from a remarkable spouse and understanding family members has worked for me. (Respondent 9, married, private university)

\section{Workplace support}

Workplace practices/support were also mentioned as another crucial source of support for women academics. 
Being a single woman, my colleagues have always been my constant source of support. They are also my sounding board. (Respondent 5, single, private university)

My boss is always supportive of our applications for emergency leave or extra parental leave. To have such support from my boss really helps to reduce the stress at work. (Respondent 7 , married, public university)

\section{Time management}

Effective time management is another coping strategy used by the women academics. The following narratives reflect the women's conscious and deliberate efforts to manage their time under the pressures of work and family demands.

When it comes to attaining WLB, I personally think effective time management is essence. I have this daily to-do list to manage my time at work and at home. The list also helps me to stay focused on what is important ... so that I won't be overwhelmed by having too many things to do in a day. (Respondent 6 , widowed, public university)

\section{Recreational and religious activities}

Only three respondents claimed to take up some form of recreational activities or hobbies (e.g., sports, meditation, yoga, painting, gardening, etc.) to destress.

I always make it a point to do some meditation before I start off my day. Meditation helps me to relax and destress. I'm also into yoga. (Respondent 5, single, private university)

Regarding religious activities, only two women said their involvement in religious activities has helped them to manage better.

My late husband was a great and constant source of support for me. With his passing... things can get stressful sometimes. But I must say that prayers help and I pray more now than before. (Respondent 10, widowed, public university)

Achour and Boerhannoeddin (2011) opines that religious coping strategies are more important and effective when individuals are confronted with events which individuals cannot handle. 


\section{Satisficing}

Satisficing as a coping strategy is an emerging theme from this study. Coined by Simon (1956), the term "satisficing" is a combination of satisfice and suffice. Satisficing means that whenever a course of action is pursued it is not for achieving optimal outcomes. The aim is just to satisfy the minimum requirements necessary to achieve a goal.

I cope by employing the "make-do principle" in carrying out my work tasks and family responsibilities. Going by this principle of doing the minimum possible, I can get things done for the day and that makes me happy. (Respondent 2, married, public university)

Another respondent claimed that she coped by making adjustments to her work schedules and would even forego any opportunities (upskilling and promotion) for the sake of her family.

To be honest, I will put my family and children first in everything that I do which includes my work. Of course, I'll still make sure that I carry out my work responsibilities. But whenever my family needs me, I'll adjust my work schedules around their needs. I don't really care much about my own career aspirations, at least not at this point of time. (Respondent 9 , married, private university)

Adema (2013) has pointed out that to accommodate family commitments, women tend to adjust their work by adjusting work schedules, choosing less demanding work, switching careers, or abdicating career advancement opportunities. Interestingly, only two women reported working harder as a coping strategy.

\section{Workplace Culture/Leadership}

The final theme which emerged from the study is workplace culture/leadership. Over half of the respondents agreed that while personal coping strategies are important, what works better is an active and collaboration between the university and lecturers to promote the WLB agenda. The following narratives echo this sentiment:

As lecturers we can only do so much. Universities should realise that if they want us to perform our job well, they will need to provide appropriate and adequate support to help us maintain WLB, especially for working mothers. (Respondent 9, married, private university)

By and large, the interview data substantiate past studies on WLB and coping strategies. The next section will discuss the findings in greater detail. 


\section{DISCUSSION}

This study revealed three key findings. First, the data suggest that the roles of and expectations from academics in both public and private universities have indeed expanded and intensified. Yet, it is interesting to note that work intensification appeared to have little effect on WLB perceptions for more than half of the respondents, corroborating the extant literature (e.g., Managing Work/Life Balance International 2007; Winefield et al. 2003). The respondents alluded this to the fact that they learnt to strike a balance between the increased work demands and family commitments. This is consistent with the perspective of proactive coping by Frone (2003), Haddock et al. (2001), Haddon and Hede (2009) and Pitt-Catsouphes et al. (2007), whereby these women took deliberate actions to maintain their WLB instead of allowing themselves to fall victim to their unfavourable circumstances.

Another finding relates to the coping strategies employed by the women academics which are generally consistent with those reported in previous studies (Haddon and Hede 2009; Stahl and Caliguiri 2005). The women also tended to rely more on problem-focused coping strategies than emotion-focused strategies. Plausibly, they viewed the "stressful" situations to be still within their control, and that they were able to deal with the fundamental cause of the stress in a more objective manner, without having their emotions get in the way. Another noteworthy finding is that whenever emotion-focused coping strategies are employed by the respondents, they are found to be positive (i.e., recreational and religious activities) rather than negative in nature.

The existing literature by Carlson and Perrewe (1999) states that three types of social support - spousal, familial and friends - are perceived as important, if not more important than workplace support in enhancing WLB experiences. Similarly, this study found that dependence on spousal and familial support emerged as the most frequently endorsed coping strategy. Workplace support came in second. The findings could be attributable to cultural characteristics and dimensions which are said to drive and shape the preference, pattern and process of coping among individuals (Chun, Moos and Cronkite 2006; Kuo et al. 2018). To elaborate, the interdependence of Asian culture which values sharing and collaboration will give rise to "collectivistic coping" (Kuo, Arnold and RodriguezRubio 2014; Yeh, Arora and Wu 2006) or "cultural coping" (Kuo et al. 2018). In particular, the notion of collectivistic coping or cultural coping represents relationally, communally, and collectively oriented coping behaviour which is supported by the prevailing cultural theories of stress coping (Chun, Moos and Cronkite 2006). While this coping strategy has been found among white Europeans (Kuo, Arnold and Rodriguez-Rubio 2014), its prevalence is noted more among Asian Americans and Asian Canadians (Kuo et al. 2018). This study extends the existing literature by validating that collectivistic coping is also prevalent among Malaysian academics. 
Apart from the familial and social support, the narratives of the women also accentuate the importance of the workplace culture/leadership in providing support to help academics experience better WLB. The question now is "why should the university be involved in the promotion of WLB?" Friedman et al. (2000) contend that this is because the business value can be enormous. Top management needs to realise that moving up the world university rankings does not only depend on the number of grants or publications academics have obtained. The real long-term competitiveness and sustainability of a university also lies in the physical and mental well-being of academics to carry out the targets (Lanthois 2017), which can only be achieved if the academics experience a reasonable WLB. Unfortunately, the interview data denote that the constant work demands of academics may have eroded time and energy for personal life of the women given that only a handful of them cited recreational and religious activities as effective coping strategies. It is hence reiterated that crucial considerations for research and provision of WLB programmes in the university must be extended beyond the provision of familyfriendly benefits (e.g., career breaks and extra parental leave entitlements) to creating a health-promoting culture in the university which aims at improving the overall quality of life for academics (Littig 2008).

Another top coping strategy cited by the women academics is time management. The significance of time management as a coping tactic has been constantly cited in the literature (e.g., Acker and Armenti 2007). Lewis's study on Swiss academics viewed time as "a sort of vacuum into which work- and nonwork activities are filled" (Lewis 2016, 74). This study revealed that the women academics tended to fill their time with more non-work activities by adjusting their work schedules in the interests of their family commitments rather than the other way around. Only two women indicated that they coped by working harder/bringing work home though this was mentioned when describing how their academic work has intensified. It can be surmised that working harder/bringing work home could be a response to increasing work demands rather than a strategy to cope with the demands.

Satisficing is another emerging theme as a coping strategy of the women academics. Engaging in this form of bound rationality in making decisions at work and at home is understandable considering the finite amount of time and resources available to academics, particularly women. Mothers are likely to have very limited opportunity and time for leisure as they must juggle between motherhood and employment (Hilbrecht et al. 2008).

In sum, the findings of this study cannot claim to speak for all women academics but hope to have provided knowledge suspended in the realities of these women's experiences so that their needs can be addressed in the WLB for sustainable development agenda. 


\section{LIMITATIONS AND FUTURE RESEARCH}

There are some limitations which we need to consider when interpreting the results of the present study. First, the women sample inherently limits the generalisability of the findings to male academics. Thus, future studies should target bigger samples which include both men and women academics. Future research should also explore discerning effective coping strategies for both genders. Women and men are said to develop differing coping strategies when dealing with intense conflicts in work and life (Bray et al. 2001; Haar 2006). The current study can also be extended to cover various levels of analysis which include situational, environmental and individual characteristics in order to broaden our understanding of WLB (Haddon and Hede 2009). Future works may also explore the potential influence of demographic variables (e.g., age group, marital status, the size of family, the age of children and the work hours) and personality traits (e.g., emotional intelligence, locus of control and self-efficacy) on perceptions of WLB and well-being. Examining other antecedents influencing the selection of coping strategies such as marital status and personal characteristics may also be another future research opportunity. It will also be interesting for future research to address the role and effects of cultural coping in response to academic work intensification and work stress specifically (Kuo et al. 2018).

The knowledge gained from a more extensive work on WLB can aid in the development of research-based policy advice and practical information that addresses modern realities and meets the needs of 21st century families (ILO 2017). Future research should also demonstrate efforts to link the debate on sustainability with the debate on a gender-sensible labour and welfare policy. This synergetic field of research will remain a highly important research area (Littig 2008).

\section{CONCLUSION}

With the changing nature and composition of the workplace in the higher education sector, academics (particularly women) are experiencing greater challenges in terms of reconciling work-family demands. While recognising the fact that workfamily conflicts can cause decreased WLB, this article shifts the focus to women's coping strategies which are deemed to be more important in determining personal outcomes and WLB experience. It is hoped that the preliminary findings of this study can be utilised as a supportive framework or foundation for sustainable development of women in academia. 


\section{ACKNOWLEDGEMENTS}

The manuscript is a part of a larger study supported by Universiti Sains Malaysia Short-term Grant No: 304/PKANITA/6313262.

\section{REFERENCES}

Achour, M. and A. Boerhannoeddin. 2011. The role of religiosity as a coping strategy in coping with work-family conflict: The case of Malaysian women in academia. International Journal of Social Science and Humanity 1(1): 80-85. https://doi.org/10.7763/ijssh.2011.v1.14

Acker, S. and C. Armenti. 2007. Sleepless in academia. Gender and Education 16(1): $3-24$.

Adema, W. 2013. Greater gender equality: What role for family policy. Family Matters 93(1): 7-16.

Agosti, M.T., A. Bringsen and I. Andersson. 2017. The complexity of resources related to work-life balance and well-being: A survey among municipality employees in Sweden. The International Journal of Human Resource Management 28(16): 2351-2374. https://doi.org/10.1080/09585192.2017.1340323

Ajayi, F., S. Ojo and C. Mordi. 2015. Work-family balance and coping strategies among women: Evidence from commercial banks in Nigeria. European Journal of Business and Management 7(2): 152-160.

Ang, M.C.H., T. Ramayah, C.L. Goi and Noraida Endut. 2018. Work-life balance in higher education: Are work intensification and emotional labor potential job stressors? Asian Pacific Journal of Advanced Business and Social Studies 4(2): 5-16. https://doi.org/10.25275/apjabssv4i2ss6

Bexley, E., S. Arkoudis and R. James. 2013. The motivations, values and future plans of Australian academics. Higher Education 65(3): 385-400. https://doi.org/10.1007/ s10734-012-9550-3

Bray, R.M., C.S. Camlin, J.A. Fairbank, G.H. Dunteman and S.A. Wheeless. 2001. The effects of stress and job functioning of military men and women. Armed Forces and Society 27(3): 397-417. https://doi.org/10.1177/0095327x0102700304

Carlson, D.A. and P.L. Perrewe. 1999. The role of social support in the stressor-strain relationship: An examination of work-family conflict. Journal of Management 25(4): 513-540. https://doi.org/10.1177/014920639902500403

Chun, C.A., R.H. Moos and R.C. Cronkite. 2006. Culture: A fundamental context for stress and coping paradigm. In Handbook of multicultural perspectives on stress and coping, eds. P.T.P. Wong and L.C.J. Wong, 29-53. New York: Springer. https://doi.org/10.1007/0-387-26238-5_2

Deery, M. and L. Jago. 2009. A framework for work-life balance practices: Addressing the needs of the tourism industry. Tourism and Hospitality Research 9(2): 97-108. https://doi.org/10.1057/thr.2009.4 
Edwards, J.R. and N.P. Rothbard. 2000. Mechanisms linking work and family: Specifying the relationships between work and family constructs. The Academy of Management Review 25(1): 178-199. https://doi.org/10.5465/amr.2000.2791609

Ferguson, M., D. Carlson, S. Zivnuska and D. Whitten. 2012. Support at work and home: The path to satisfaction through balance. Journal of Vocational Behavior 80(2): 299-307. https://doi.org/10.1016/j.jvb.2012.01.001

Friedman, S.D., D. Steward, P. Christensen and J. DeGroot. 2000. Work and life: The end of the zero-sum game. Harvard Business Review on Work and Life Balance 76(6): 119-129.

Frone, M.R. 2003. Work-family balance. In Handbook of occupational health psychology, eds. J.C. Quick and L.E. Tetrick, 143-162. Washington, DC: American Psychological Association. https://doi.org/10.1037/10474-007

Gatta, M.L. and P.A. Roos. 2004. Balancing without a net in academia: Integrating family and work lives. Equal Opportunities International 23(3-5): 124-142. https://doi.org/10.1108/02610150410787765

Goo, C.C., M.C.H. Ang and M.T. Goi. 2018. Work intensification and turnover intention in academia: The mediating role of work-life balance. Journal of Asian Scientific Research, Asian Economic and Social Society 8(5): 188-196. https://doi.org/ 10.18488/journal.2.2018.85.188.196

Gowan, M.A., C.M. Riordan and R.D. Gatewood. 1999. Test of a model of coping with involuntary job loss following a company closing. Journal of Applied Psychology 84(1): 75-86. https://doi.org/10.1037/0021-9010.84.1.75

Grawitch, M.J., L.K. Barber and L. Justice. 2010. Rethinking the work-life interface: It's not about balance, it's about resource allocation. Applied Psychology: Health and Well-Being 2(2):127-159. https://doi.org/10.1111/j.1758-0854.2009 .01023.x

Greenhaus, J.H., K.M. Collins and J.D. Shaw. 2003. The relation between work-family balance and quality of life. Journal of Vocational Behavior 63(1): 510-531. https://doi.org/10.1016/s0001-8791(02)00042-8

Haar, J.M. 2006. The downside of coping: Work-family conflict, employee burnout and the moderating effects of coping strategies. Journal of Management and Organization 12(1): 146-159. https://doi.org/10.1017/s1833367200004089

Haddock, S.A., S.J. Ziemba, T.S. Zimmerman and L.R. Current. 2001. Ten adaptive strategies for family and work balance: Advice from successful families. Journal of Marital and Family Therapy 27(4): 445-458. https://oi.org/ 10.1111/j.1752-0606.2001.tb00339.x

Haddon, B. and A. Hede. 2009. Work-life balance: In search of effective strategies. Proceedings of 23rd Australian and New Zealand Academy of Management (ANZAM) Annual Conference, Australia. 2-4 December.

Hertz, R. 1999.Working to place family at the center of life: Dual-earner and single-parent strategies, The ANNALS of the American Academy of Political and Social Science 562(1): 16-31. https://doi.org/10.1177/0002716299562001002

Hilbrecht, M., S.M. Shaw, L.C. Johnson and J. Andrey. 2008. Contradictory implications for work-life balance to teleworking mothers. Gender, Work \& Organization 15(5): 454-476. https://doi.org/10.1111/j.1468-0432.2008.00413.x 
International Labor Office (ILO). 2017. Work-life balance. http://www.ilo.org/global/ topics/working-time/wl-balance/lang--en/index.htm (accessed 30 December 2017).

Kinman, G. and F. Jones. 2008. A life beyond work? Job demands, work-life balance, and wellbeing in UK academics. Journal of Human Behaviour in the Social Environment 17(1-2): 41-60. https://doi.org/10.1080/10911350802165478

Kuo, B.C.H., R. Arnold and B. Rodriguez-Rubio. 2014. Mediating effects of coping in the link between spirituality and psychological development of the cross-cultural coping scale: Collective, avoidance, and engagement strategies. Mental Health, Religion and Culture 17(2): 173-184. https://doi.org/10.1080/13674676.2013 .780015

Kuo, B.C.H., K.M. Soucie, S. Huang and R. Laith. 2018. The mediating role of cultural coping behaviours on the relationships between academic stress and psychological well-being outcomes. International Journal of Psychology 53(1): 27-36. https://doi.org/10.1002/ijop.12421

Lanthois, P. 2017. The key to a sustainable business and a sustainable life. http:/www. evancarmichael.com/library/dr-paul-lanthois/Work-Life-Balance-The-KeyTo-A-Sustainable-Business-and-A-Sustainable-Life.html (accessed 30 January 2018).

Lewis, R.A. 2016. Work-life balance in academia: Experiences of lecturers in Switzerland. International Journal of Business and Management 4(1): 69-84. https://doi.org/ 10.20472/bm.2016.4.1.004

Littig, B. 2008. Work-life balance: Catchword or catalyst for sustainable work? Sociological Series 85(1): 1-14.

Lunau, T., C. Bambra, T.A. Eikemo, K.A. van der Wel and N. Dragano. 2014. A balancing act? Work-life balance, health and well-being in European welfare states. European Journal of Public Health 24(3): 422-427. https://doi.org/10.1093/ eurpub/cku010

Managing Work/Life Balance International. 2007. Work/life initiatives: The way ahead report on the year 2007 survey. Roseville, NSW: Work/Life Balance International.

O'Reilly, M. and N. Parker. 2012. Unsatisfactory saturation: A critical exploration of the notion of saturated sample sizes in qualitative research. Qualitative Research 13(2): 190-197. https://doi.org/10.1177/1468794112446106

Parker, K. and W. Wang. 2013. Modern parenthood: Roles of moms and dads converge as they balance work and family. PEW Research Center, Washington DC. http://www.pewsocialtrends.org/2013/03/14/modern-parenthood-roles-of-momsand-dads-converge-as-they-balance-work-and-family (accessed 1 March 2017). https://doi.org/10.18574/nyu/9780814749159.003.0004

Pitt-Catsouphes, M., M.A. Smyer, C. Matz-Costa and K. Kane. 2007. The national study report: Phase II of the national study of business strategy and workforce development. Chestnut Hill, MA: Center on Aging and Work at Boston College. https://doi.org/10.3886/icpsr34734

Quick, J.D., A.B. Henly and J.C. Quick. 2004. The balancing act: At work and at home. Organizational Dynamics 33(4): 426-438. https://doi.org/10.1016/ j.orgdyn.2004.09.008 
Rao, I. 2017. Work-life balance for sustainable human development: Cultural intelligence as enabler. Journal of Human Behavior in the Social Environment 27(7): 706-713. https://doi.org/10.1080/10911359.2017.1327391

Rothbard, N.P. 2001. Enriching or depleting? The dynamics of engagement in work and family roles. Administrative Science Quarterly 46(1): 655-684. https://doi.org/10.2307/3094827

Safiah Sidek, Mohd Taib Dora, Norliah Kudus, Mahadi Abu Hassan, Sazelin Arif, Shahrulanuar Mohamed, Noor Azlin Bidin and Mohd Fadzil Mohd Idris. 2015. Achieving excellence in academic work practices: The experience of Malaysian distinguished professors. Asian Social Science 11(17): 83-89. https://doi.org/ 10.5539/ass.v11n $17 \mathrm{p} 83$

Santos, G. and C. Cabral-Cardoso. 2008. Work-family culture in academia: A gendered view of work-family conflict and coping strategies. Gender Management: An International Journal 23(6): 442-457. https://doi.org/10.1108/175424108 10897553

Simon, H.A. 1956. Rational choice and the structure of the environment. Psychological Review 63(2): 129-138.

Stahl, G.K. and P. Caligiuri. 2005. The effectiveness of expatriate coping strategies: The moderating role of cultural distance, position level and time on the international assignment. Journal of Applied Psychology 90(4): 603-615. https://doi.org/10.1037/0021-9010.90.4.603

Tan-Wilson, A. and N. Stamp. 2015. College students' views of work-life balance in stem research careers: Addressing negative preconceptions. CBE Life Sciences Education 14(3): 1. https://doi.org/10.1187/cbe.14-11-0210

The Star. 2017. Budget 2018: Goodies for the disabled, childcare boost. 27 October. https://www.thestar.com.my/news/nation/2017/10/27/budget-2018-newoffice-buildings-must-have-childcare-facilities/ (accessed 18 December 2017).

Winefield, A.H., N. Gillespie, C. Stough, J. Dua, J. Hapuarachchi and C. Boyd. 2003. Occupational stress in Australian university staff. International Journal of Stress Management 10(1): 51-63. https://doi.org/10.1037/1072-5245.10.1.51

Yeh, C.J., A.K. Arora and K.A. Wu. 2006. A new theoretical model of collectivistic coping. In International and cultural psychology series: Handbook of multicultural perspectives on stress and coping, eds. P.T.P. Wong and L.C.J. Wong, 55-72. Dallas, TX: Spring Publications. https://doi.org/10.1007/0-387-26238-5_3

Zheng, C., K. Kashi, D. Fan, J. Molineux and M.S. Ee. 2016. Impact of individual coping strategies and organisational work-life balance programmes on Australian employee wellbeing. The International Journal of Human Resource Management 27(1): 501-526. https://doi.org/10.1080/09585192.2015.1020447 